\title{
Multiple non-polypoid mucosal Schwann cell hamartomas presenting as edematous and submucosal tumor-like lesions: a case report
}

\author{
Takeshi Okamoto ${ }^{*}$, Takaaki Yoshimoto and Katsuyuki Fukuda
}

\begin{abstract}
Background: Mucosal Schwann cell hamartomas are rare neurogenic tumors which present most commonly in the distal colon. They are usually discovered as small, single polyps in asymptomatic patients.

Case presentation: An asymptomatic 64-year-old man was referred to us after a $12 \mathrm{~mm}$ subepithelial lesion was discovered incidentally on screening colonoscopy. Follow-up colonoscopy conducted 2 months later revealed that the tumor had disappeared, leaving multiple edematous, submucosal tumor-like elevations presenting as skip lesions throughout the sigmoid colon. Lesions had elongated pits on magnifying endoscopy and were limited to the first layer on endoscopic ultrasound. Biopsies revealed unclearly delineated foci of spindle-shaped cells limited to the lamina propria. On immunohistochemistry, all lesions were positive for S-100 protein and negative for CD34, CD56, and neurofilament protein. The patient was diagnosed with multiple mucosal Schwann cell hamartomas of the sigmoid colon. He remains asymptomatic after 18 months of follow-up, but the lesions have also remained unchanged.
\end{abstract}

Conclusion: We report a case of multiple non-polypoid mucosal Schwann cell hamartomas. Endoscopic findings may assist in the differential diagnosis, particularly when presenting as non-polypoid, submucosal tumor-like lesions.

Keywords: Polyp, Neurogenic tumor, Harmatomatosis, Colonoscopy, Case report

\section{Background}

Mucosal Schwann cell hamartomas $(\mathrm{MSCH})$ are rare neurogenic lesions found in the lamina propria of the gastrointestinal tract. They arise most commonly in the distal colon and are generally asymptomatic small, single sessile polyps which may be discovered incidentally on screening colonoscopy [1]. MSCH has also been reported in the gastroesophageal junction [2], gastric antrum [3], and gallbladder [4].

The differential diagnosis of neurogenic tumors in the colon includes mucosal neuroma which is associated

*Correspondence: okamotot@luke.ac.jp

Department of Gastroenterology, St. Luke's International Hospital, 9-1 Akashicho, Chuo-ku, Tokyo 104-8560, Japan with multiple endocrine neoplasia type 2B (MEN 2B), neurofibroma which is associated with neurofibromatosis type 1 (NF1), schwannoma, ganglioneuroma, intramucosal perineuroma, and mucosal benign epithelioid nerve sheath tumor $[1,2]$. MSCH can be distinguished histologically, by proliferation of uniform spindle cells with unclear cell borders and dense eosinophilic cytoplasm and elongated nuclei in the lamina propria which entrap colonic crypts, and on immunohistochemistry, with Schwann cells positive for S-100 protein, generally negative for neurofilament protein (NFP), and negative for other stains including CD34, smooth muscle actin, and epithelial membrane antigen $[1,2,5,6]$.

While there are currently over 80 reports of colorectal $\mathrm{MSCH}$ in the English literature, reports of non-polypoid 
MSCH and of multiple MSCH are scarce [2, 7]. Furthermore, endoscopic findings in $\mathrm{MSCH}$ have not been reported in detail, as most authors have focused on its pathological aspects. Herein, we report a case of multiple non-polypoid, edematous and submucosal tumor-like MSCH spanning most of the sigmoid colon discovered incidentally on screening colonoscopy. We also consider the narrow-band imaging (NBI) and endoscopic ultrasound findings of $\mathrm{MSCH}$.

\section{Case presentation}

A 64-year-old man was referred to our hospital after a $12 \mathrm{~mm}$ subepithelial lesion in the sigmoid colon was discovered incidentally on screening colonoscopy (Fig. 1a). The referring physician's biopsy report stated that only non-specific mucosal changes were observed. The patient had a history of hypertension treated with calcium channel blockers and angiotensin II receptor blockers, type 2 diabetes mellitus treated with a selective dipeptidyl peptidase-4 inhibitor, and atrial fibrillation treated with a direct oral anticoagulant. He was in his ordinary state of health, had regular bowel movements, and denied any abdominal symptoms.
Follow-up colonoscopy conducted 2 months later revealed that the tumor had disappeared completely, leaving numerous edematous, submucosal tumor-like protrusions presenting as skip lesions throughout the sigmoid colon, over a length of $15 \mathrm{~cm}$ (Fig. 1b, c). Some lesions had fine white granular opacities on their surface on NBI, while others did not (Fig. 1d). All lesions displayed elongated crypt openings, increased width of intervening parts, and no visible microvessels on magnifying NBI (Fig. 1e). Endoscopic ultrasound revealed mild, homogeneously hypoechoic thickening of the first layer (superficial mucosa) with no apparent second layer (deep mucosa) involvement (Fig. 1f). Six tubular adenomas ( 4 in the transverse colon, 2 in the sigmoid colon), one serrated adenoma in the sigmoid colon, and four hyperplastic polyps in the sigmoid colon were resected during the same session. One of the resected hyperplastic polyps in the sigmoid colon was located on top of one of the elevated lesions with white granular opacities (Fig. 2a, b). Computed tomography with contrast was unremarkable, confirming no clear tumor or thickening of the colonic wall.

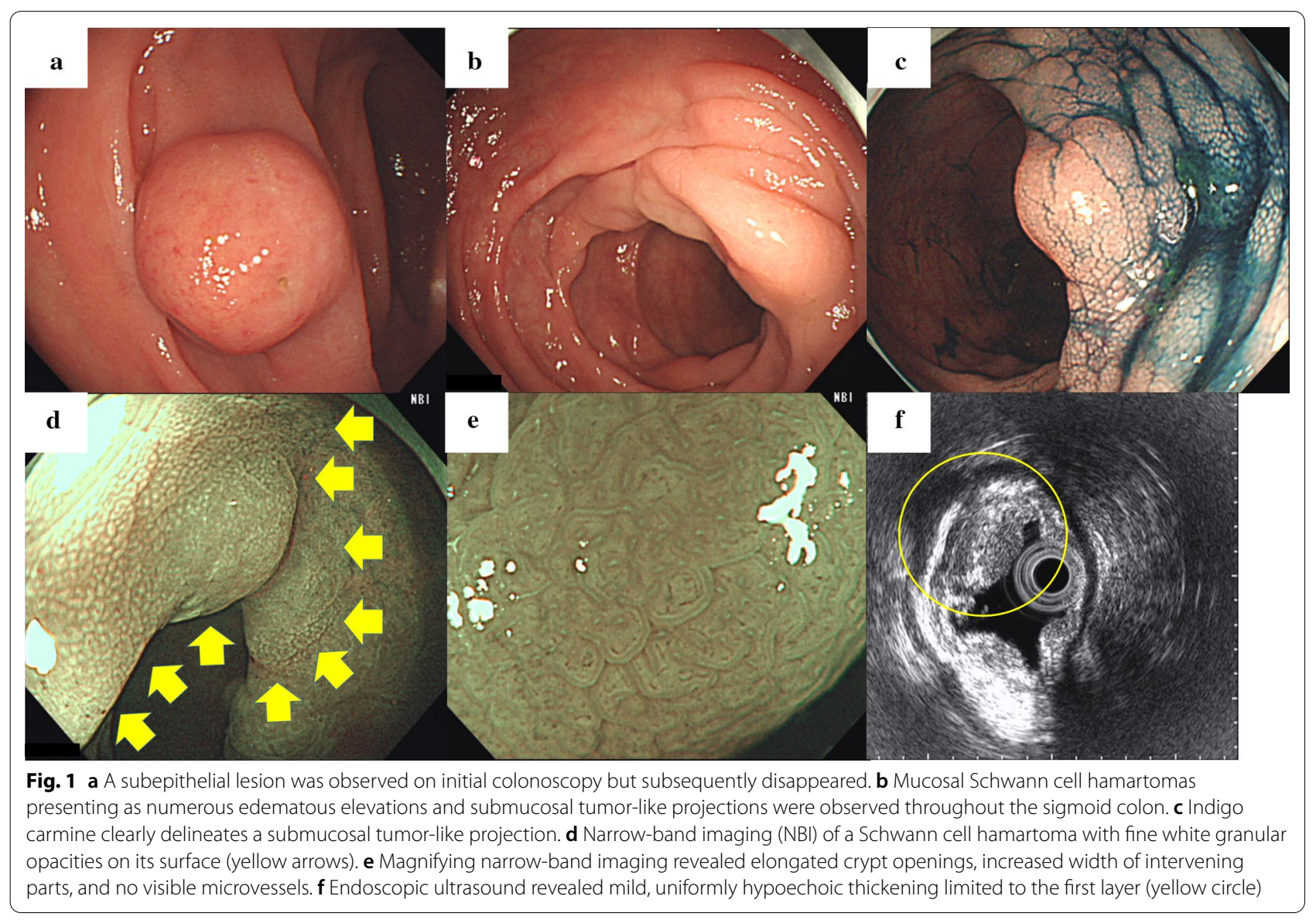




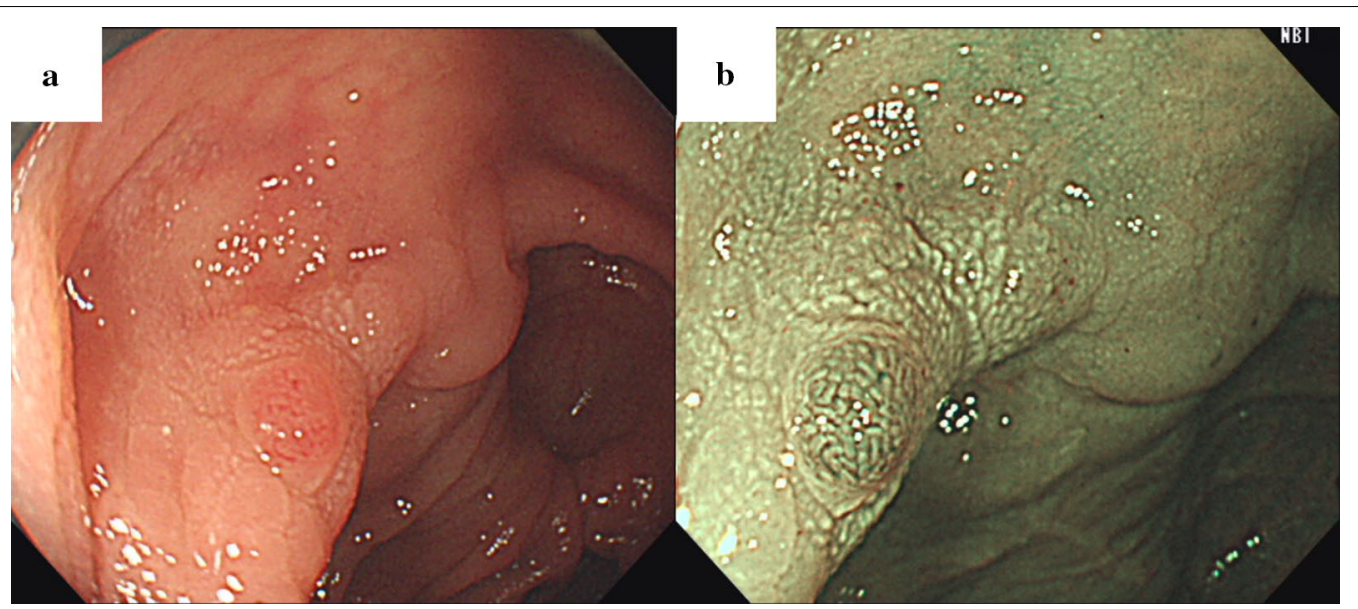

Fig. 2 a A hyperplastic polyp was located on top of one of the mucosal Schwann cell hamartomas elevated lesions with white granular opacities. $\mathbf{b}$ Narrow-band imaging of the hyperplastic polyp and mucosal Schwann cell hamartoma

Multiple biopsies of the thickened mucosa all revealed proliferation of uniform spindle-shaped cells in the lamina propria (Fig. 3a-c). Eosinophilic cytoplasm with unclear cell borders and tapered or elongated nuclei were observed. Crypts and goblet cells were preserved. Edema and mild lymphocytic and plasma cell infiltration were observed in the interstitium. Schwann cells positive for S-100 protein and negative for CD34, CD56, and NFP were identified on immunohistochemistry (Fig. $3 \mathrm{~d}-\mathrm{g}$ ).
Stains for pan-cytokeratin (AE/AE3) and desmin were also negative, as were chromogranin A and synaptophysin stains conducted on biopsies which included submucosal tissue.

Upon detailed questioning, the patient denied any personal or family history of café au lait spots, neurofibromatosis, or thyroid or adrenal disease which could suggest MEN 2B or NF1. No relevant findings were found in a dermatological examination, laboratory tests, or

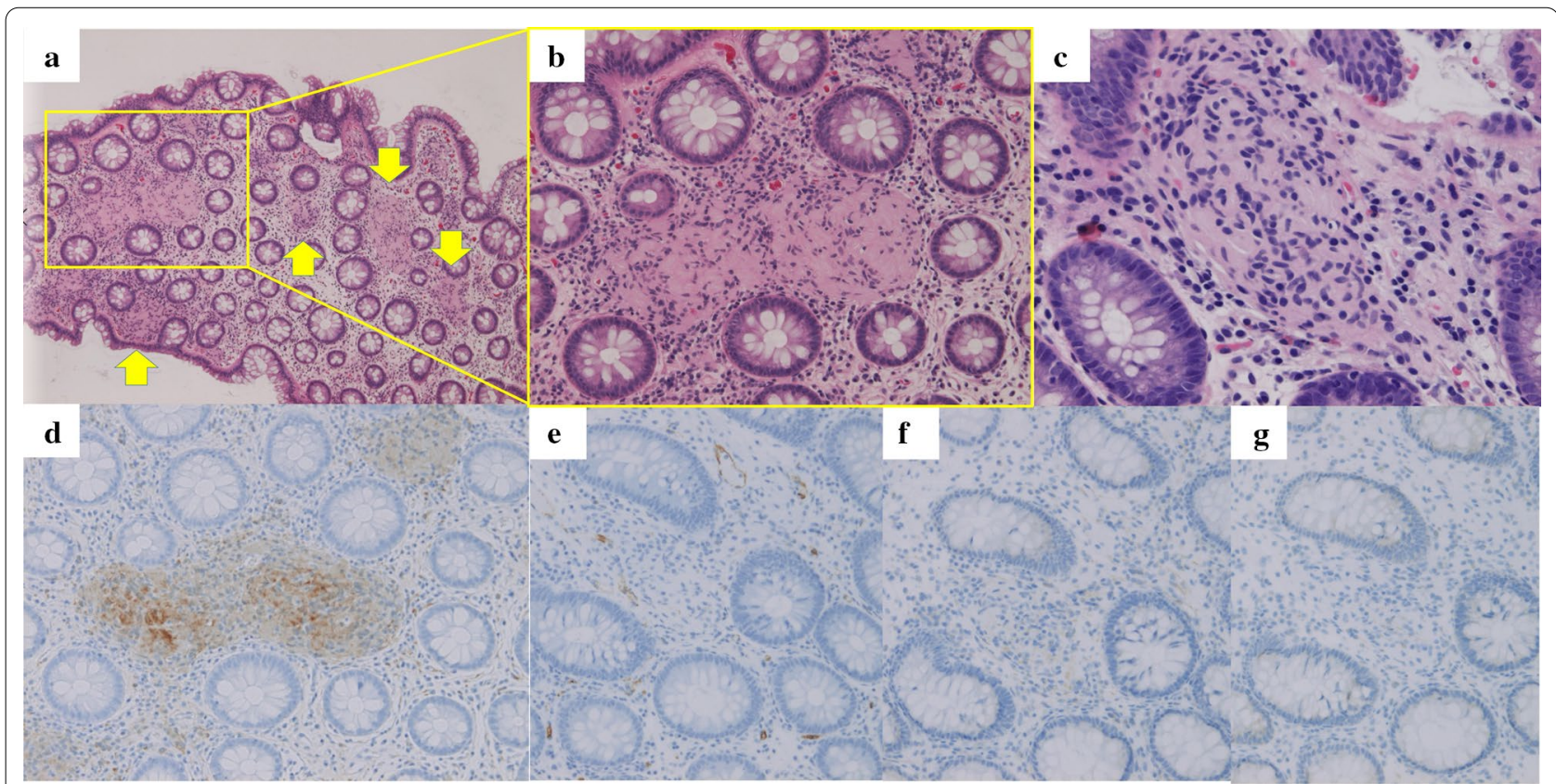

Fig. 3 a Low-power and b, c high-power magnification of mucosal Schwann cell hamartomas (yellow arrows). Immunohistochemistry: d S-100 protein, e CD34, $\mathbf{f} C D 56$, and $\mathbf{g}$ neurofilament protein stains 
in imaging studies. Based on the above, the patient was diagnosed with multiple MSCH of the sigmoid colon.

The patient remains asymptomatic without treatment during 18 months of follow-up. However, the multiple $\mathrm{MSCH}$ lesions in the sigmoid colon remain unchanged despite frequent colonoscopies. Pathological findings consistent with $\mathrm{MSCH}$ are also observed on follow-up biopsies taken at every colonoscopy.

\section{Discussion and conclusion}

Gibson et al. [1] first reported 26 cases of MSCH presenting as sessile polyps $1-6 \mathrm{~mm}$ in diameter, most of which were asymptomatic. Subsequent reports were limited to single cases until Li et al. [2] reported $48 \mathrm{MSCH}$ cases of the colon as well as $6 \mathrm{MSCH}$ cases of the gastroesophageal junction. The authors also summarized the 85 reported cases of $\mathrm{MSCH}$ in the English literature. In the 86 cases including ours, the average age was 60.2 years and $47.7 \%$ were male. Most were found distal to the splenic flexure (77.9\%), particularly the sigmoid colon $(47.7 \%)$. While $81.0 \%$ were undergoing screening colonoscopy, other indications for colonoscopy included bleeding, diarrhea or loose stools, abdominal pain, and constipation (Table 1).

Bae et al. [7] reported the only case of multiple $\mathrm{MSCH}$, referred to as mucosal Schwann cell hamartomatosis. In that case, colonoscopy conducted on a young man with abdominal discomfort and loose stools revealed a polyp in the mid-rectum and polyposis-like mucosal changes in the distal rectum. The mid-rectum polyp and one of 3

Table 1 Summary of reported colorectal cases of mucosal Schwann cell hamartoma $(n=86)$

\begin{tabular}{llr}
\hline & $\mathbf{n}$ & $\%$ \\
\hline Location & 3 & 3.5 \\
Appendiceal orifice & 2 & 2.3 \\
Cecum & 7 & 8.1 \\
Ascending colon & 7 & 8.1 \\
Transverse colon & 16 & 18.6 \\
Descending colon & 41 & 47.7 \\
Sigmoid colon & 2 & 2.3 \\
Rectosigmoid colon & 8 & 9.3 \\
Rectum & & \\
Indication/symptoms & 67 & 77.9 \\
Screening & 8 & 9.3 \\
Bleeding & 4 & 4.7 \\
Diarrhea/loose stools & 3 & 3.5 \\
Pain & 1 & 1.2 \\
Constipation & 1 & 1.2 \\
Ulcerative colitis & 2 & 2.3 \\
Unknown &
\end{tabular}

biopsies taken from polyposis-like mucosa revealed histological findings consistent with $\mathrm{MSCH}$. On the other hand, biopsies were taken from 5 distinct mucosal lesions in our case, all of which were consistent with $\mathrm{MSCH}$. The fact that our case was asymptomatic despite the large area of the colon occupied by MSCH may be interpreted as further indirect evidence that $\mathrm{MSCH}$ is harmless and does not cause symptoms. However, follow-up is desirable as long-term prognosis has not been documented.

There are only 3 other reports of non-polypoid MSCH. The first presented as many small whitish nodules somewhat similar to lesions found in our case, the second discovered incidentally on random biopsy conducted for evaluation of chronic diarrhea, and the third was located at the mass base following endoscopic mucosal resection $[2,8]$. It is also interesting to note that a hyperplastic polyp was observed on top of a $\mathrm{MSCH}$ in our case, which has never been reported.

Details on endoscopic MSCH findings in the literature are scarce [8]. Elongated crypt openings, increased width of intervening parts, and no visible microvessels on magnifying NBI with or without white granular opacities were consistently observed in the multiple lesions of our case and may assist in the differential diagnosis during colonoscopy. Lesions were limited to the first layer on endoscopic ultrasound, which can clearly differentiate MSCH from submucosal tumors. This is also consistent with $\mathrm{MSCH}$ being localized in the lamina propria on histology. In cases where MSCH mimics submucosal tumors, this finding may help prevent unnecessary endoscopic or surgical resection.

The cause of the vanishing tumor identified by the referring physician remains a mystery. Reports of vanishing colonic tumors include cytomegalovirus infection, angioedema resulting from acquired type II C1-inhibitor deficiency, and colorectal cancer [9-11]. Vanishing tumor due to anisakiasis has been reported in the stomach and can most likely also occur in the colon [12]. Spontaneous regression of various tumors such as neuroendocrine tumors has also been reported, particularly after biopsy [13]. However, our patient was asymptomatic, was believed to be immunocompetent in spite of his wellcontrolled diabetes mellitus, and had no history of raw fish ingestion. The biopsy taken from the surface of the sigmoid tumor only revealed mucosal tissue, making it unlikely that a submucosal tumor existed and regressed spontaneously due to insult from the biopsy. While we can provide no evidence, the proximity of the vanished tumor to the MSCH lesions led us to suspect an association. More research is required to determine whether or not $\mathrm{MSCH}$ can present as a vanishing tumor.

In conclusion, we report a case of multiple $\mathrm{MSCH}$ presenting as edematous, submucosal tumor-like lesions in 
the sigmoid colon. NBI and endoscopic ultrasound findings may help the endoscopist to suspect atypical $\mathrm{MSCH}$ which does not take the form of a small sessile polyp. Discovery of similar cases may shed light on the pathogenesis of this seemingly harmless entity in the future.

\section{Abbreviations}

MSCH: Mucosal Schwann cell hamartoma; MEN 2B: Multiple endocrine neoplasia type 2B; NF1: Neurofibromatosis type 1; NFP: Neurofilament protein; NBI: Narrow-band imaging.

\section{Acknowledgements}

The authors would like to thank Dr. Naoki Kanomata, Department of Pathology, St. Luke's International Hospital for his pathological diagnosis and advice on the pathological aspects of this case.

\section{Authors' contributions}

TO wrote the manuscript. TO and TY performed the colonoscopies and cared for the patient. TY and KF critically reviewed and revised the manuscript. All authors read and approved the final manuscript.

\section{Funding}

The authors have received no funding for the publication of this article.

\section{Availability of data and materials}

Not applicable.

\section{Ethics approval and consent to participate}

Not applicable.

\section{Consent for publication}

The patient provided written informed consent for the publication of this manuscript and images.

\section{Competing interests}

The authors have no competing interests to declare.

Received: 22 October 2020 Accepted: 12 January 2021

Published online: 19 January 2021

\section{References}

1. Gibson JA, Hornick JL. Mucosal Schwann cell "hamartoma": clinicopathologic study of 26 neural colorectal polyps distinct from neurofibromas and mucosal neuromas. Am J Surg Pathol. 2009;33:781-7.
2. Li Y, Beizai P, Russell JW, Westbrook L, Nowain A, Wang HL. Mucosal Schwann cell hamartoma of the gastroesophageal junction: a series of 6 cases and comparison with colorectal counterpart. Ann Diagn Pathol. 2020;47:151531.

3. Hytiroglou P, Petrakis G, Tsimoyiannis EC. Mucosal Schwann cell hamartoma can occur in the stomach and must be distinguished from other spindle cell lesions. Pathol Int. 2016;66:242-3.

4. Khanna G, Ghosh S, Barwad A, Yadav R, Das P. Mucosal Schwann cell hamartoma of gall bladder: a novel observation. Pathology. 2018;50:480-2.

5. Bae MN, Lee JE, Bae SM, Kim EY, Kim EO, Jung SH, et al. Mucosal schwanncell hamartoma diagnosed by using an endoscopic snare polypectomy. Ann Coloproctol. 2013;29:130-4.

6. Han J, Chong Y, Kim TJ, Lee EJ, Kang CS. Mucosal schwann cell hamartoma in colorectal mucosa: a rare benign lesion that resembles gastrointestinal neuroma. J Pathol Transl Med. 2017;51:187-9.

7. Bae JM, Lee JY, Cho J, Lim SA, Kang GH. Synchronous mucosal Schwanncell hamartomas in a young adult suggestive of mucosal Schwann-cell harmatomatosis: a case report. BMC Gastroenterol. 2015;15:128.

8. Sagami S, Fukumoto A, Amano M, Yamao K. A case of mucosal Schwann cell hamartoma. Nihon Shokakibyo Gakkai Zasshi. 2012;109:1776-83. (abstract only in English).

9. Kawasaki S, Osawa S, Sugimoto K, Uotani T, Nishino M, Yamada T, et al. Cecal vanishing tumor associated with cytomegalovirus infection in an immunocompetent elderly adult. World I Gastrointest Oncol. 2010;2:417-20.

10. Ebo DG, De Knop KJ, Maes JW, De Clerck LS, Stevens WJ. Vanishing tumour of the colon ascendens due to acquired type II C1-inhibitor deficiency. Acta Clin Belg. 2010;65:122-6.

11. Fujino Y, Fujio Y, Shimada E, Okazaki A. Intussusception due to vanishing colon cancer with metastasis of the regional lymph nodes: report of a case. Surg Today. 2000;30:188-90.

12. Dai Z, Kobayashi D. Gastric anisakiasis presenting as a vanishing tumor. J Gen Fam Med. 2019;20:159-60.

13. Amoroso V, Agazzi GM, Roca E, Fazio N, Mosca A, Ravanelli M, Spada F, Maroldi R, Berruti A. Regression of advanced neuroendocrine tumors among patients receiving placebo. Endocr Relat Cancer. 2017;24:L13-6.

\section{Publisher's Note}

Springer Nature remains neutral with regard to jurisdictional claims in published maps and institutional affiliations.

\footnotetext{
Ready to submit your research? Choose BMC and benefit from:

- fast, convenient online submission

- thorough peer review by experienced researchers in your field

- rapid publication on acceptance

- support for research data, including large and complex data types

- gold Open Access which fosters wider collaboration and increased citations

- maximum visibility for your research: over $100 \mathrm{M}$ website views per year
}

At BMC, research is always in progress.

Learn more biomedcentral.com/submissions 